\title{
Self-Regulation and Mastery of Musical Skills
}

\author{
Gary E. McPherson and James M. Renwick \\ (School of Music, University of Melbourne, Australia, and \\ Sydney Conservatorium of Music, University of Sydney, Australia)
}

For Publication In

Handbook of Self-Regulation of Learning and Performance

Edited by Barry Zimmerman and Dale Schunk 
Music is a basic form of human functioning (Welch \& Adams, 2003): everyone listens to music in one form or another, many defining themselves in terms of it, and most significantly, viewing musical engagement and participation as crucial to their everyday life (North, Hargreaves, \& Hargreaves, 2004). As one of the most demanding tasks for the human central nervous system (Altenmüller \& McPherson, 2008), optimal engagement in formal learning opportunities in music offers young people numerous personal and social benefits, including more developed intellectual and cognitive-emotional awareness (Schellenberg, 2006), increased social responsibility (Schellenberg, 2006), and improvements in verbal and nonverbal reasoning ability (Forgeard, Winner, Norton, \& Schlaug, 2008).

As with other skills, however, mastering a musical instrument involves many challenges. Learners need to apply themselves over long periods of time, to be able to focus their attention (particularly in demanding performance situations), to cope with the challenges of a competitive learning environment, to bounce back from setbacks inherent in the learning process, to overcome periods of self-doubt and performance slumps, and to develop a tool kit of psychological and behavioral skills that will enable them to survive the many pressures and difficulties they will encounter as they attempt to reach their goals (Martin, 2008). This perspective is particularly relevant to keep in mind for music educators who seek out ways of improving teaching and learning processes, given that many millions of children around the world begin learning a musical instrument each year, with very few continuing their engagement through to adult levels (McPherson \& Davidson, 2006).

In this chapter we will describe how we are using self-regulation theory to illuminate the mastery of musical skills by incorporating into our explanation a focus on the processes music learners activate to sustain their motivation, cognition, affect and behaviors as they strive to 
improve their performance and reach their goals. Many of the findings we cite come from a longitudinal study that has followed the musical development of 157 music learners from before they commenced their musical instrument between ages 7 and 9 , until 14 years later, after they have left school and are now working or studying at university (additional overviews of the research can be found in McPherson, 2005; McPherson \& Davidson, 2006; McPherson \& Renwick, 2001; McPherson \& Zimmerman, 2002, in press). The study involved extensive individual research sessions with the music learners, and ongoing interviews with their parents, classroom teachers and music teachers. Findings from this study will be supplemented with results from other music studies that are increasingly utilizing self-regulated learning theory as a means of updating knowledge in this area of music learning.

Current Theory in Music Skill Acquisition Highly cited music studies that have dominated literature since the 1990s investigated the biographical precursors of competence in Western music contexts. The most prominent (Ericsson, Krampe, \& Tesch-Römer, 1993; Sloboda, Davidson, Howe, \& Moore, 1996) studied the quantity and quality of experts' practice and their findings were consistent with those in other pursuits such as poetry, painting, mathematics, chess and sport (Bloom, 1985; Chase \& Ericsson, 1982; Ericsson, Charness, Feltovich, \& Hoffman, 2006) that vast amounts of practice over 10 or more years are required to perfect skills to mastery level (Weisberg, 1999). Over 10,000 hours of practice by the age of 20 (Ericsson et al., 1993) are required for a musician to develop skill to an elite level. Much of this work is based on the assumption that learning progresses in an ordered sequence (Lehmann, 1997), and that each intellectual capacity relies on completely different skills and techniques that are then applied to specific sets of knowledge and materials within any given domain of learning (Hargreaves, 1996). 
While recognizing the value of this perspective for explaining the highest levels of expert mastery, we have always felt uneasy about using it as a means of understanding typical musical development, because our research reveals that each individual's pathway to positive musical engagement is explained more convincingly by understanding how social experiences, personal beliefs, as well as formal and informal learning opportunities, interact (McPherson, Davidson, \& Faulkner, forthcoming; McPherson \& O'Neill, in press). Our studies indicate that the likelihood of development being principally linear is small, especially when a variety of changing and multiple musical interests exist, and when entrances to and departures from musical engagement and learning are traced. For this reason, we have chosen to adopt the social cognitive explanation of self-regulated learning theory to trace the acquisition of musical skills from the beginning to advanced stages.

What have we learned from our studies? Like any academic or motor task, learning a musical instrument requires a great deal of self-regulation. For skill on an instrument to develop optimally, young musicians need to learn how to utilize many varied behaviors to improve their performance. They need to manage and plan their own practice, to react to their own and others' performance by choosing, modifying and adapting their strategies, to structure and control the setting where their learning takes place, and to actively seek help from knowledgeable others or available resources. As we will show in the sections that follow, mastery of musical skills occurs most efficiently when various socializing processes work in accord with each other to scaffold learners to adopt self-initiated mechanisms for monitoring and controlling their own performance (McPherson \& Zimmerman, 2002, in press). 


\section{Phases and Subphases of Self-Regulation}

Possessing self-regulatory skills is one thing, but it is an entirely different matter to "apply them persistently in the face of difficulties, stressors, or competing distractions" (Zimmerman, 1995, p. 219). Unlike other areas such as academic learning, music research is only beginning to focus on the processes whereby students learn to mobilize, direct, and sustain their efforts through the self-enhancing cycles of learning (forethought, performance, and self-reflection) that are basic to self-regulated learning theory (Zimmerman, 2000; Zimmerman \& Campillo, 2003). To date, few attempts have been made in the music literature to integrate understandings by tracking how each of these processes acts to enhance or impede learning, practice and performance.

As shown in Figure 1, forethought refers to the cognitive processes and the personal beliefs a musician holds prior to performance that can subsequently enhance learning, with the performance phase involving processes occurring during learning that affect concentration and performance, and self-reflection involving the musician's subsequent response to the experience. These three processes are cyclical, because the musician's self-reflection feeds back into forethought to influence future learning efforts and performance (Zimmerman, 2000). We base the central part of this chapter on Zimmerman and Campillo's (2003) model as shown in Figure 1, with its considerable power to explain the self-regulated problem-solving of successful musicians, as well as the deficits in the less efficient work of musical novices.

\section{Forethought Phase}

Forethought can occur in two major ways as a student learns a musical instrument (see Figure 1). The first - task analysis - involves being able to set goals and strategically plan one's learning, while the second involves such self-motivational beliefs as self-efficacy, outcome expectations, task valuing and goal orientations. 


\section{Task Analysis}

Goal setting and strategic planning. In the aforementioned longitudinal study, the children were interviewed and tested individually at the end of their first, second and third year of learning to determine the extent of their instrumental progress and to collect information on the motivational beliefs they held for continuing to learn their instrument.

Among the skills tested was the young learners' ability to practice repertoire at home that they had been assigned by their teacher, and our work involved mapping out how the students organized their practice sessions and kept track of what they were learning. Across each of the first three years of learning, significant differences were found in performance achievement according to various aspects of goal setting and strategic planning (McPherson, 2005). For example, students who scored higher on a measure of the performance of rehearsed repertoire tended to actively keep track in their practice diary of what they were learning, and organized their practice so that they started by working on the pieces assigned by their teacher before ending their practice session with the pieces they wished to play for enjoyment (in contrast to playing for pleasure first and for improvement afterwards).

For the students' self-reports of how they practiced, we coded responses in four categories showing ascending levels of self-regulation: (1) a superficial approach to practicing (e.g., "I play my pieces through just once-I want to get them over with"), (2) playing the piece a couple of times with little evidence of any concentrated effort (e.g., "I do each piece about twice, out of habit"), (3) more sophisticated strategies of playing the piece a few times until it had improved (e.g., "I try to make it better by playing it over and over"), and (4) the most selfregulated behavior, where students showed a more concentrated ability to refine their playing (e.g., "First I play it once and see how good I am, then I practice it again and again until it's at a 
standard that I can take to my tutor"). As with our other analyses, these categories, from least strategic to most self-regulated, were significantly related to the students' overall level of performance when controlling for practice time (McPherson, 2005).

The young learners were also tested individually at the end of each year to measure their performance ability across a range of dimensions, from performing pieces using notation, to playing repertoire from memory and by ear (McPherson, 2005). A content analysis of the children's comments resulted in the identification of specific cognitive problem solving strategies for each type of performance skill, and these were found to be closely associated with the young learner's actual level of skill as measured on the battery of performance achievement measures. For example, as shown in Figure 2, the sight-reading strategies involved a scale that added together all the strategies the young learners used to familiarize themselves with the music in the seconds before performing pieces for the first time on a standardized test. These strategies included studying the first measure of the music to gain a sense of how the piece commenced, actively searching to find the key- and time-signatures, establishing an appropriate tempo by thinking about how the piece should sound, and scanning the entire work to identify possible obstacles, so that the piece could be played in an appropriate style and tempo that would help facilitate an accurate performance. Our playing by ear measure (where students had to perform short melodies that they heard from a recorded model) encompassed a number of conceptual strategies, such as using a "visual" approach that was unconnected to the instrument (e.g., "I was trying to think what notes they were and thinking how they go up and down and how they would look in music") through to more kinesthetic strategies (e.g., "I tried to play the first part of the piece in the gap and when I heard it again I tried to add the next part - I was thinking about how the notes would be fingered on my clarinet") and on to the most musically sophisticated 
strategies displaying a highly developed capacity to coordinate ear and hand (e.g., a child who demonstrated accurate singing of the passage while showing how she silently fingered it on her flute while listening to the taped example).

Several studies have used self-report and observation to map the slow but crucial development of planning abilities as students gain musical mastery. Novices generally show very little evidence of goal setting or strategic planning, but instead rely on a rote "play-through" approach (Hallam, 2001; McPherson \& Renwick, 2001). With external contingencies, such as the approach of examinations, higher levels of planning of what material to practice have been observed in intermediate-level students (Hallam, 2001; Renwick, McPherson, \& McCormick, 2008). This increase in planning often goes hand-in-hand with the increasing length of pieces of music, and the increasing complexity of the additional exercises students are required to practice. Advanced students (Hallam, 2001; Nielsen, 2001) and professional musicians (Chaffin \& Logan, 2006; Hallam, 2001) can show evidence of the high-level planning typical of experts in other domains. Even at this level, however, interesting individual differences have been documented in approaches to planning throughout a practice session (Hallam, 1995), with some musicians engaging in extensive planning of the whole practice session in advance and others tending towards more intuitive, serial planning throughout the session (analogous individual differences have been described in composers, such as the pre-planning Mozart and the constantly revising Beethoven; Hargreaves, 1986).

\section{Self-motivation beliefs}

Consistent with Zimmerman's (2000) cyclical model, recent music research has started to investigate the ways in which various motivational beliefs instigate effortful engagement in musical problem-solving. Work on the crucial role of self-efficacy (McCormick \& McPherson, 
2003; McPherson \& McCormick, 2006; Merrick, 2006; Nielsen, 2004) has been supplemented by investigations of the way musicians' self-regulation is prompted by their goal orientation (Nielsen, 2008), perceived autonomy (Renwick, 2008), task valuing (McCormick \& McPherson, 2007) and interest in the repertoire they are practicing (Renwick \& McPherson, 2002).

Self-efficacy. This belief has been shown to be linked to the level at which students initiate and sustain their self-regulatory efforts (Bandura, 1997; Zimmerman \& Kitsantas, 2005), so it is no surprise that learners who are highly self-efficacious are better positioned to perform at a higher level than others who lack confidence in their own ability. This has been shown in two music studies, involving 332 (aged 9 to 18; McCormick \& McPherson, 2003) and then 686 (aged 9 to 19 ; McPherson \& McCormick, 2006) young musicians preparing for examinations on their musical instrument conducted by two different external organizations. In such highly charged music performance examinations, candidates have only one opportunity to perform at their best and there is no time to revise or correct an earlier decision, or to make more time available for one sub-task as compared to another. Consequently, it is not surprising that musicians' perceptions of their ability to successfully perform demanding literature in front of an examiner should play such a major role in how they performed. In both studies, self-efficacy was the best predictor of the young musicians' performance results - even better than the amount of practice they were undertaking in preparation for their examination. In this way, the students' perception of how well they thought they would do on the examinations seemed to boost their engagement in the performance phase of their problem-solving (i.e., effortful practice), and consequently the way they came prepared to complete their performance requirements.

A similar study (Nielsen, 2004) of relations between self-efficacy and self-regulated learning strategy use was conducted with an older sample of tertiary music students, using an 
adapted form of the Motivated Strategies for Learning Questionnaire (MSLQ; Pintrich, Smith, Garcia, \& McKeachie, 1993). Self-efficacy was found to be significantly associated with the use of eight of the nine forms of cognitive and metacognitive strategies addressed by the MSLQ (interestingly, excepting "rehearsal", which may be a default strategy for musicians).

Outcome expectations. Self-regulated learners are not only motivated by their perceptions of their capability to successfully perform a task, but also by the outcomes they expect to stem from it. The role of outcome expectations has not been addressed systematically in music, but some research findings lend support to its importance. In one study (McPherson \& McCormick, 2000), achievement in a graded examination was most strongly predicted by estimates by the participants — collected immediately before the examination — of the result they would achieve.

The notion that many candidates are strongly motivated by a desire to achieve a high mark in their instrumental performance examination was confirmed in our recent study (Renwick, McCormick, \& McPherson, 2009), which focused on the role of perceptions of autonomy in engagement in self-regulated musical practicing. Factor analysis of a questionnaire derived from self-determination theory (Ryan \& Connell, 1989) showed a very high level of endorsement of items concerned with success in the examination (e.g., "I try to do well in my exam because I will feel really proud of myself if I do well.”) In structural equation modeling, this factor showed significant relations with self-regulated learning behaviors, such as selfmonitoring (e.g., "I think about how many mistakes I'm making and how I can correct them") and the use of corrective strategies (e.g. "I write on my music things I need to remember").

Task valuing and interest. In an optional activity such as learning a musical instrument, students' perceptions of its importance, utility, and intrinsic interest are crucial in motivating them to engage in the effortful and sustained building of mastery (McCormick \& McPherson, 
2007; Pintrich \& De Groot, 1990). Many of these notions of task value are implicit in our recent study of the relations between autonomous motivation and self-regulated music practicing (Renwick et al., 2009), where the strongest predictor of self-regulation was a construct related to intrinsic motivation (e.g., "I practice my instrument because I love playing my instrument") and an internalized notion of its importance ("I practice my instrument because it's important to me to do my practice.”) In follow-up case studies (Renwick, 2008), one sixteen-year-old saxophonist described his shift from high levels of extrinsic motivation to his current highly intrinsic motivation:

I did piano for a very long time and I remember when I sat exams there was always a reward for me. Like if I did well, then ... I'd get something. Like I was young, it was a motivation to practice, because it was always a big hassle to get me to work.... I've loved saxophone ever since I started in the end of Year 7 (I'm in Year 10 now). I've loved it, I've played it, I've enjoyed it. I don't need any motivation.... And now, because I'm like older, I don't really get a reward-just the self-satisfaction of passing the grade well.

Clearly for this young musician, music-making had become an activity motivated by a strong personal interest and an optimal balance of challenge and skill (Csikszentmihalyi, Rathunde, \& Whalen, 1997). In an earlier case study (Renwick \& McPherson, 2002), we observed a remarkable instance of the effect on self-regulated strategy use of a powerful emerging interest in a particular musical genre. Detailed computer analysis was conducted of learning behavior for seven children practicing naturalistically in their own home over three years (McPherson \& Renwick, 2001), and generally very low levels of strategy use were observed in these novices aged 8 to 12 . For instance, in the third year of learning, the children 
showed very low levels of perseverance, spending $92 \%$ of their time on the first run-through of a piece.

With one twelve-year-old clarinetist, "Clarissa", however, there was a segment of practicing that showed notably higher levels of self-regulation, while playing the Woody Herman tune Golden Wedding (Renwick \& McPherson, 2002). Whereas this youngster generally spent an average of 0.79 seconds on each note in her pieces, in Golden Wedding she showed remarkable perseverance when facing difficulties and spent nearly 10 seconds on each note: a twelve-fold increase. Clarissa also returned to work on the piece in the observed practice session two more times, when in every other Year 3 observation, she only ever played a piece once before moving on. The moment-by-moment strategy use also showed remarkably higher levels of sophistication: strategies typically found in much more advanced musicians — such as silent fingering on the instrument, singing, and strategic alteration of the tempo-were observed only in Golden Wedding.

When we interviewed Clarissa about her practice on Golden Wedding, she explained why she was so strongly motivated. With her typical low-level strategy use, Clarissa had been learning La Cinquantaine, the original Classical version of Golden Wedding. At one point in her lesson, Clarissa's teacher mentioned that he played a "jazzy" version of this melody in his swing band, and he demonstrated it for her. Fascinated by this appealing melody, which she could easily connect with her emerging personal interest in jazz, Clarissa asked her teacher to notate the new version in her notebook. This was the sole instance Clarissa could recall of being allowed to choose her own repertoire. While of course limited in its generalizability, this vignette strikes us as a powerful example of the effect of interest and choice on self-regulated learning and mastery-oriented strategy use. 
Goal orientation. Closely related to notions of task value and intrinsic interest, achievement goals have received some preliminary attention in the music literature in terms of their relationship with strategic practicing behaviors. In a study of US instrumental majors at college, Smith (2005) found correlations between self-regulated practicing and task goal orientations, but no relationship with either ego-approach or ego-avoid goals. In a Norwegian study of advanced students (Nielsen, 2008), a similar pattern of results was found, although in this study there were negative relations between ego-avoid goals and the use of learning strategies, consistent with research in academic settings (Elliot, McGregor, \& Gable, 1999).

\section{Performance Phase}

For the performance phase (see Figure 1), and consistent with self-regulated learning theory (Zimmerman \& Campillo, 2003), we are focusing on two processes that we believe enable learners to optimize their performance, namely self-observation and self-control while actively engaged in a problem-solving episode, such as attempting a run-through of a difficult section of a piece. This phase of the cycle is distinct in musical performance, as various factors, such as the impossibility of thinking aloud and the special auditory nature of the target performance, make self-observation and self-control especially challenging-especially for novices (McPherson \& Renwick, 2001).

\section{Self-Observation}

Our interpretation of self-regulated learning concentrates first on the ways in which musicians monitor their playing before we turn to the self-control processes that they implement to improve their performance. Consequently, the performance process starts with selfobservation, which for musicians often involves mentally tracking one's performance (in contrast to self-recording, which refers to keeping a physical record). Researchers who study self- 
observation as it relates to motor skills recommend limiting metacognitive monitoring to key processes or outcomes, as too much monitoring can interfere and disrupt one's performance (B. Green \& Gallwey, 1986, provide practical advice on this matter). Self-observation can be complicated even further by the fact that as skills are acquired, less intentional monitoring is required as skills become automatic.

Lehmann and Ericsson (1997) have encapsulated several elements of the musician's problem-solving task in a model of three types of mental representation: (1) an aural image of the goal performance - that is, of how the piece should sound; (2) a motor representation of the physical actions necessary to realize this goal representation; and (3) a representation of the current online performance, which is constantly monitored for discrepancies with the other mental representations. This balancing of information in working memory requires a student musician to read up to seven notes ahead of what they are playing at the time (Sloboda, 1984) while actively monitoring the accuracy of the sounds that have been just produced: a task similar to simultaneous translation. Typically, then, the type of feedback and self-monitoring that occurs in music performance involves adjusting and correcting one's performance after playing wrong notes or reacting to the aural or visual cues in other musicians' performances during the act of performance. In such cases various types of feedback act as a cue for musicians to sense how to correct themselves, focus their attention, or devise appropriate strategies for shaping or correcting their performance (see also, McPherson, 1994).

\section{Self-Control}

Self-instruction, task strategies, attention focusing, and imagery. Self-control processes help musicians focus on their performance and what they are playing because they help optimize their efforts, through such means as self-instruction (overtly or covertly describing how to 
execute a task), imagery, attention focusing and task strategies. For example, we observed Clarissa (the young clarinetist mentioned earlier; Renwick \& McPherson, 2002) stop and talk to herself during her practice of Golden Wedding, and we interpreted this act as an important way for her to reinforce what she needed to do in order to master this melody. Self-instruction of this type helps students to monitor and control their concentration during learning (Vygotsky, 1986). Other forms of inner self-speech (e.g., "I can do this!") and imagery to create "mental blueprints" of specific goals or tasks are also commonly used by musicians to strengthen their ability to focus attention on the performance and alleviate performance anxiety (McPherson \& Zimmerman, 2002, in press).

Successful musicians are also those who have learned how to apply themselves during their practice, by blocking out distractions and concentrating more effectively on what they are practicing or performing. This can often involve simple environmental structuring, such as finding a quiet place to practice (McPherson \& Renwick, 2001), but can also contain a crucial element of emotional self-regulation, as students deal with the considerable frustrations involved in their repeated unsuccessful attempts to match their performance with their goal representation (Austin \& Berg, 2006).

Efficient musical practice is reliant on how well musicians are able to incorporate into their practice sessions those strategies that maximize potential, especially when trying to master difficult challenges. For example, young musicians who break a difficult work down into smaller units, which can be isolated and practiced separately, are likely to be more successful and attentive as they practice than players who perform the same piece from beginning to end without more concentrated efforts to refine the sections in which they are having difficulty. Indeed, various key behaviors during the performance phase of self-regulated learning are related 
to superior achievement. These strategies share the key characteristic of breaking down a difficult problem into more manageable tasks, such as the repetition of musically meaningful sections (Gruson, 1988; Miksza, 2006, 2007), marking the score to assist with remembering important aspects (Miksza, 2006; Renwick, 2008) and strategic selection of a section of the piece, breaking it down, and then recombining the material (Miksza, 2006, 2007). Expert musicians (Chaffin \& Logan, 2006; Miklaszewski, 1989) are highly strategic in using musical structure to organize their self-regulated problem-solving; for instance, Miksza (2007) found superior learning was associated to the frequency with which college musicians implemented the strategy of jumping to the beginning of a harder section of the piece, rather than slavishly playing through an easier section first. Typically, experts utilize such strategies in a highly systematic and flexible, but also automatic, manner (Chaffin \& Logan, 2006).

\section{Self-Reflection Phase}

Self-reflection can occur in four ways: self-evaluation, causal attributions, selfsatisfaction/affect, and adaptivity (see Figure 1; Zimmerman \& Campillo, 2003). The performance of music is an exacting art form, so musicians make constant self-evaluations of their progress to compare their performance with others or to react to the feedback they receive from a conductor or other musicians. Self-regulated musicians keenly evaluate their performance, comparing it both with their peers and with outstanding models to which they strive to emulate. Hewitt (2001) investigated the effect of introducing a systematic process of self-evaluation alongside the use of exemplary recorded models in intermediate musicians' learning of new pieces. While previous research has found mixed results in terms of the efficacy of providing students with recorded templates, Hewitt found that such models were only effective if coupled with systematic self-evaluation. 
Such self-evaluations often lead to attributions about the causal meaning of the result, and are therefore pivotal processes in self-reflection. Ideally, musicians attribute their success or failure to correctable causes that can be improved through more effort and attention, even during long stretches where practice sessions are frustrating and do not explicitly produce improvement (Zimmerman, 2000). Such self-judgments are integrally related to the satisfaction or dissatisfaction derived from performing well or poorly, and the conclusions one then makes for improving future efforts to learn or perform. As with any area of learning, self-satisfaction perceptions impact on how and why musicians choose to engage in activities and other forms of music making that are satisfying and which make them feel good, while they avoid experiences and tasks that are frustrating or result in anxiety (Bandura, 1991). As Zimmerman (2000) indicates, self-satisfaction is the means by which "people give direction to their actions and create self-incentives to persist in their efforts. Thus, a person's motivation does not stem from the goals themselves, but rather from self-evaluative reactions to behavioral outcomes" (p. 23). For instance, the intrinsically motivated saxophonist described above (Renwick, 2008) made several references in a think-aloud protocol to the satisfaction he derived from recognizing his successes throughout the practice session: "I was thinking I was actually happy because normally I don't do so well around here. I was thinking, you know, these are just one of the good times that I just get it right."

When musicians draw conclusions about their efforts, they may make adaptive inferences that can direct them to new or better forms of performance self-regulation, such as choosing a better or more effective strategy (Austin \& Vispoel, 1998; Zimmerman \& Martinez-Pons, 1992). On the other hand, defensive inferences tend to limit personal growth, especially in situations 
where a musician feels helpless, procrastinates, avoids tasks, or ceases active engagement due to apathy (Garcia \& Pintrich, 1994).

Because self-reactions affect forethought processes, they can dramatically impact on the decisions musicians make to define their most important goals (Zimmerman, 2000). In such cases self-satisfaction can strengthen a musician's self-efficacy beliefs for mastering challenging new repertoire, their learning goal orientations and intrinsic interest in the task. When musicians' self-motivational beliefs are enhanced they are more likely to feel inclined to continue their cyclical self-regulatory efforts in order to attain their goals. In contrast, when they are reduced, musicians are less likely to feel confident about their ability and less intrinsically motivated to devote further energy to improving their performance. The road to achieving musical excellence as a performer is long and arduous, and there will be times in every musician's lifespan when feelings of self-efficacy will dramatically change after a particularly rewarding or disappointing performance.

Musical Applications of Research on Self-Regulation: the Cyclical Phases in Action The Norwegian music educator Siw Nielsen (1999a, 1999b, 2001, 2008) has pioneered the application of self-regulated learning theory to music, exploring and identifying the learning strategies of music students at the Norwegian Academy of Music as they prepare pieces for performance. Based on the results of her analyses, Nielsen (2001) has proposed a model (see Figure 3) that depicts four types of problem-solving alternatives utilized by her talented selfregulated organists.

In Figure 3, solid black arrows are used to indicate the problem to be solved, the musician's strategy use, the performance of the piece, and the level of self-evaluation of the performance. In her analyses, Nielsen shows that when the musicians evaluated the success of 
their performance as successful in terms of making progress, they tended to focus on a new problem (the full grey arrows in the model). At other times when they evaluated their performance as unsuccessful but believed in the value of the chosen strategy for solving the musical problem, they increased their effort and continued using the same strategy (the light grey dotted arrows). In situations where the musicians evaluated their performance as unsuccessful and did not feel that the strategy being used was appropriate to the identified problem, they would again search their metacognitive knowledge, revise the strategy and continue problem solving (the darker grey dotted arrows). A fourth option (shown with black dotted arrows) occurred when evaluation of an unsuccessful performance led to the conclusion that the nature of the original problem had not been correctly identified; in this situation, a revised problem belief would lead to revised strategies, all mediated through sophisticated metacognitive knowledge and self-regulation.

Nielsen's (2001) model highlights some of the processes adopted by advanced music students who were skillful in their use of self-regulatory processes which can be used as the basis for developing techniques that she believes optimize learning at this and other levels of musical proficiency. Most aptly, her studies demonstrate that skillful self-regulating students reflect on their learning, and make this a part of a cyclical process that involves systematic forethought and performance control. To enhance task analysis, she recommends teaching student to ask and answer questions such as "What is my problem?”, “How can I solve it?”, and "How am I doing?" during their lessons and individual practice. Students at the music academy are also taught to take into account contextual factors that affect the efficiency of a strategy, especially with regard to variations in task and setting. Students become more aware of what they need to do to improve their performance when they understand how more complex material affects and 
constrains a learning strategy as compared to easier material, and how their goals for the problems to solves at a given time affect their choice of learning strategies (Nielsen, 2001).

Conclusions and Future Research Directions

Throughout this chapter we have described how self-regulated learning theory is helping to redefine and update conceptions of how musicians acquire musical skills, and what can be done to maximize learners' musical potential. Based on existing research, there is now clear evidence that the theoretical approaches that have been used to study academic areas of learning — and especially the self-regulation framework-have relevance to studying musical skills.

Even though self-regulated learning theory has only recently gained the attention of the music research community, we are excited that more music researchers are beginning to adopt this approach as a means of examining the efficiency of musicians' learning and the ways in which students can be better educated. Because of the onerous complexity of analyzing musical problem-solving, much of this work remains at the level of descriptive case studies, however, and among the many challenges for music researchers is the use of techniques for studying the dynamic nature of the self-regulatory cycle, as in the microanalyses reported by Kitsantas and Zimmerman (e.g., 2002). We are aware of virtually no research in the music domain explicitly attempting to teach self-regulatory skills to music students, despite ample evidence of the success of such programs elsewhere (Schunk \& Zimmerman, 1998).

As music research develops more rigorous techniques to address major issues, results from music studies will inevitably start to expand thinking in other domains of self-regulated learning theory. Much attention in current music-learning research is focused on the way that adolescents learn in "informal" contexts, such as garage bands (Campbell, 1995; L. Green, 2001), often acquiring high levels of skill without assistance from a teacher, and where their 
learning patterns resemble a kind of "fun" version of the study group (or cooperative learning environment). Future research in musical self-regulated learning would benefit from a detailed analysis of how such environments feed motivation and skill development through the reciprocal involvement of peers in the problem-solving task. While self-regulated learning has typically been investigated from the perspective of an individual dealing with relatively well-structured problems, such an expansion of research focus would help educators to understand the intrinsically social nature of musical skill acquisition in ways that would clarify how conscious and unconscious efforts by musicians impact on the host of technical and interpretative skills that characterize musical expertise. The extent to which self-regulated and socially mediated learning environments imply different motivational structures within should also be a high research priority as music education moves from a predominantly reproductive to a more creative focus.

In conclusion, the self-regulation framework has considerable practical potential for helping to develop more informed evidence-based approaches to the learning and teaching of music. The results of studies cited in this chapter show that the framework has validity even though there are many important questions still remaining to be resolved. 


\section{References}

Altenmüller, E., \& McPherson, G. E. (2008). Motor learning and instrumental training. In W. Gruhn \& F. Rauscher (Eds.), Neurosciences in music pedagogy (pp. 121-144). New York: Nova Biomedical Books.

Austin, J. R., \& Berg, M. H. (2006). Exploring music practice among sixth-grade band and orchestra students. Psychology of Music, 34, 535-558.

Austin, J. R., \& Vispoel, W. P. (1998). How American adolescents interpret success and failure in classroom music: Relationships among attributional beliefs, self-concept and achievement. Psychology of Music, 26, 26-45.

Bandura, A. (1991). Self-regulation of motivation through anticipatory and self-reactive mechanism. In R. A. Dienstbier (Ed.), Nebraska Symposium on Motivation: Vol. 38. Perspectives on motivation (pp. 69-164). Lincoln: University of Nebraska Press.

Bandura, A. (1997). Self-efficacy: The exercise of control. New York: Freeman.

Bloom, B. S. (1985). Generalizations about talent development. In B. S. Bloom (Ed.), Developing talent in young people (pp. 507-549). New York: Ballantine Books.

Campbell, P. S. (1995). Of garage bands and song-getting: The musical development of young rock musicians. Research Studies in Music Education, 4, 12-20.

Chaffin, R., \& Logan, T. (2006). Practicing perfection: How concert soloists prepare for performance. Advances in Cognitive Psychology, 2(2-3), 113-130.

Chase, W. G., \& Ericsson, K. A. (1982). Skill and working memory. In G. H. Bower (Ed.), The psychology of learning and memory: Advances in research and theory (Vol. 16, pp. 158). San Diego, CA: Academic Press. 
Csikszentmihalyi, M., Rathunde, K., \& Whalen, S. (1997). Talented teenagers: The roots of success and failure. Cambridge, England: Cambridge University Press.

Elliot, A. J., McGregor, H. A., \& Gable, S. (1999). Achievement goals, study strategies, and exam performance: A mediational analysis. Journal of Educational Psychology, 91, 549563.

Ericsson, K. A., Charness, N., Feltovich, P. J., \& Hoffman, R. R. (Eds.). (2006). The Cambridge handbook of expertise and expert performance. New York: Cambridge University Press.

Ericsson, K. A., Krampe, R. T., \& Tesch-Römer, C. (1993). The role of deliberate practice in the acquisition of expert performance. Psychological Review, 100, 363-406.

Forgeard, M., Winner, E., Norton, A., \& Schlaug, G. (2008). Practicing a musical instrument in childhood is associated with enhanced verbal ability and nonverbal reasoning. PLoS ONE, 3, e3566.

Garcia, T., \& Pintrich, P. R. (1994). Regulating motivation and cognition in the classroom: The role of self-schemas and self-regulatory strategies. In D. H. Schunk \& B. J. Zimmerman (Eds.), Self-regulation of learning and performance: Issues and educational applications (pp. 127-153). Hillsdale, NJ: Erlbaum.

Green, B., \& Gallwey, W. T. (1986). The inner game of music. Garden City, NY: Anchor Press/Doubleday.

Green, L. (2001). How popular musicians learn: A way ahead for music education. Aldershot, England: Ashgate.

Gruson, L. M. (1988). Rehearsal skill and musical competence: Does practice make perfect? In J. A. Sloboda (Ed.), Generative processes in music: The psychology of performance, improvisation, and composition (pp. 91-112). Oxford: Clarendon Press. 
Hallam, S. (1995). Professional musicians' approaches to the learning and interpretation of music. Psychology of Music, 23, 111-128.

Hallam, S. (2001). The development of expertise in young musicians: Strategy use, knowledge acquisition and individual diversity. Music Education Research, 3, 7-23.

Hargreaves, D. J. (1986). The developmental psychology of music. Cambridge, England: Cambridge University Press.

Hargreaves, D. J. (1996). The development of artistic and musical competence. In I. Deliège \& J. A. Sloboda (Eds.), Musical beginnings: Origins and development of musical competence (pp. 145-170). Oxford: Oxford University Press.

Hewitt, M. P. (2001). The effects of modeling, self-evaluation, and self-listening on junior high instrumentalists' music performance and practice attitude. Journal of Research in Music Education, 49, 307-322.

Kitsantas, A., \& Zimmerman, B. J. (2002). Comparing self-regulatory processes among novice, non-expert, and expert volleyball players: A microanalytic study. Journal of Applied Sport Psychology, 14, 91-105.

Lehmann, A. C. (1997). The acquisition of expertise in music: Efficiency of deliberate practice as a moderating variable in accounting for sub-expert performance. In I. Deliège \& J. A. Sloboda (Eds.), Perception and cognition of music (pp. 161-187). Hove, England: Psychology Press.

Lehmann, A. C., \& Ericsson, K. A. (1997). Research on expert performance and deliberate practice: Implications for the education of amateur musicians and music students. Psychomusicology, 16, 40-58. 
Martin, A. J. (2008). Motivation and engagement in music and sport: Testing a multidimensional framework in diverse performance settings. Journal of Personality, 76, 135-170.

McCormick, J., \& McPherson, G. E. (2003). The role of self-efficacy in a musical performance examination: An exploratory structural equation analysis. Psychology of Music, 31, 3751.

McCormick, J., \& McPherson, G. E. (2007). Expectancy-value motivation in the context of a music performance examination. Musica Scientice, Special issue, 37-50.

McPherson, G. E. (1994). Factors and abilities influencing sightreading skill in music. Journal of Research in Music Education, 42, 217-231.

McPherson, G. E. (2005). From child to musician: Skill development during the beginning stages of learning an instrument. Psychology of Music, 33, 5-35.

McPherson, G. E., \& Davidson, J. W. (2006). Playing an instrument. In G. E. McPherson (Ed.), The child as musician: A handbook of musical development (pp. 331-351). Oxford: Oxford University Press.

McPherson, G. E., Davidson, J. W., \& Faulkner, R. (forthcoming). Music in our lives: Redefining musical development, ability and identity. Oxford: Oxford University Press.

McPherson, G. E., \& McCormick, J. (2000). The contribution of motivational factors to instrumental performance in a music examination. Research Studies in Music Education, $15,31-39$.

McPherson, G. E., \& McCormick, J. (2006). Self-efficacy and music performance. Psychology of Music, 34, 322-336. 
McPherson, G. E., \& O'Neill, S. (in press). Children's and adolescent's motivation to learn music as compared to other school subjects: An eight country mapping exercise. Research Studies in Music Education.

McPherson, G. E., \& Renwick, J. M. (2001). A longitudinal study of self-regulation in children's musical practice. Music Education Research, 3, 169-186.

McPherson, G. E., \& Zimmerman, B. J. (2002). Self-regulation of musical learning: A social cognitive perspective. In R. Colwell \& C. Richardson (Eds.), The new handbook of research on music teaching and learning (pp. 327-347). New York: Oxford University Press.

McPherson, G. E., \& Zimmerman, B. J. (in press). Self-regulation of musical learning: A social cognitive perspective on developing performance skills. In R. Colwell \& P. Webster (Eds.), MENC Handbook of Research on Music Learning, Volume 1: Strategies. New York: Oxford University Press.

Merrick, B. M. (2006). The relationship between self-efficacy and self-regulated behaviour within a secondary school music technology based creative learning environment (Doctoral dissertation). Retrieved from http://handle.unsw.edu.au/1959.4/25768

Miklaszewski, K. (1989). A case study of a pianist preparing a musical performance. Psychology of Music, 17, 95-109.

Miksza, P. (2006). Relationships among impulsiveness, locus of control, sex, and music practice. Journal of Research in Music Education, 54, 308-323.

Miksza, P. (2007). Effective practice: An investigation of observed practice behaviors, selfreported practice habits, and the performance achievement of high school wind players. Journal of Research in Music Education, 55, 359-375. 
Nielsen, S. G. (1999a). Learning strategies in instrumental music practice. British Journal of Music Education, 16, 275-291.

Nielsen, S. G. (1999b). Regulation of learning strategies during practice: A case study of a single church organ student preparing a particular work for a concert performance. Psychology of Music, 27, 218-229.

Nielsen, S. G. (2001). Self-regulating learning strategies in instrumental music practice. Music Education Research, 3, 155-167.

Nielsen, S. G. (2004). Strategies and self-efficacy beliefs in instrumental and vocal individual practice: A study of students in higher music education. Psychology of Music, 32, 418431.

Nielsen, S. G. (2008). Achievement goals, learning strategies and instrumental performance. Music Education Research, 10, 235-247.

North, A. C., Hargreaves, D. J., \& Hargreaves, J. J. (2004). Uses of music in everyday life. Music Perception, 22, 41-77.

Pintrich, P. R., \& De Groot, E. V. (1990). Motivational and self-regulated learning components of classroom academic performance. Journal of Educational Psychology, 82, 33-40.

Pintrich, P. R., Smith, D. A. F., Garcia, T., \& McKeachie, W. J. (1993). Reliability and predictive validity of the Motivated Strategies for Learning Questionnaire (MSLQ). Educational and Psychological Measurement, 53, 810-813.

Renwick, J. M. (2008). Because I love playing my instrument: Young musicians' internalised motivation and self-regulated practising behaviour (Doctoral dissertation). Retrieved from http://handle.unsw.edu.au/1959.4/36701 
Renwick, J. M., McCormick, J., \& McPherson, G. E. (2009, August). Defining relationships between motivational beliefs and self-regulated practising behaviours using a structural equation model. Paper presented at the 7th triennial conference of the European Society for the Cognitive Sciences of Music, Jyväskylä, Finland.

Renwick, J. M., \& McPherson, G. E. (2002). Interest and choice: Student-selected repertoire and its effect on practising behaviour. British Journal of Music Education, 19, 173-188.

Renwick, J. M., McPherson, G. E., \& McCormick, J. (2008, July). Effort management, selfmonitoring and corrective strategies in the practising behaviour of intermediate instrumentalists: Observations and retrospective think-aloud protocols. Paper presented at the International Society for Music Education world conference, Bologna, Italy.

Ryan, R. M., \& Connell, J. P. (1989). Perceived locus of causality and internalization: Examining reasons for acting in two domains. Journal of Personality and Social Psychology, 57, 749-761.

Schellenberg, E. G. (2006). Exposure to music: The truth about the consequences. In G. E. McPherson (Ed.), The child as musician: A handbook of musical development (pp. 111134). Oxford: Oxford University Press.

Schunk, D. H., \& Zimmerman, B. J. (Eds.). (1998). Self-regulated learning: From teaching to self-reflective practice. New York: Guilford Press.

Sloboda, J. A. (1984). Experimental studies in music reading: A review. Music Perception, 2, $222-236$.

Sloboda, J. A., Davidson, J. W., Howe, M. J. A., \& Moore, D. G. (1996). The role of practice in the development of performing musicians. British Journal of Psychology, 87, 287-309. 
Smith, B. P. (2005). Goal orientation, implicit theory of ability, and collegiate instrumental music practice. Psychology of Music, 33, 36-57.

Vygotsky, L. S. (1986). Thought and language (Rev. ed.). Cambridge, MA: MIT Press.

Weisberg, R. W. (1999). Creativity and knowledge: A challenge to theories. In R. J. Sternberg (Ed.), Handbook of creativity (pp. 226-250). Cambridge: Cambridge University Press.

Welch, G., \& Adams, P. (2003). How is music learning celebrated and developed? Southwell, UK: British Educational Research Association.

Zimmerman, B. J. (1995). Self-efficacy and educational development. In A. Bandura (Ed.), Selfefficacy in changing societies (pp. 202-231). New York: Cambridge University Press.

Zimmerman, B. J. (2000). Attaining self-regulation: A social cognitive perspective. In M.

Boekaerts, P. R. Pintrich \& M. Zeidner (Eds.), Handbook of self-regulation (pp. 13-39). San Diego, CA: Academic Press.

Zimmerman, B. J., \& Campillo, M. (2003). Motivating self-regulated problem-solvers. In J. E. Davidson \& R. J. Sternberg (Eds.), The psychology of problem solving (pp. 233-262). New York: Cambridge University Press.

Zimmerman, B. J., \& Kitsantas, A. (2005). Homework practices and academic achievement: The mediating role of self-efficacy and perceived responsibility beliefs. Contemporary Educational Psychology, 30, 397-417.

Zimmerman, B. J., \& Martinez-Pons, M. (1992). Perceptions of efficacy and strategy use in the self-regulation of learning. In D. H. Schunk \& J. L. Meece (Eds.), Student perceptions in the classroom (pp. 185-207). Hillsdale, NJ: Erlbaum. 
Figure 1

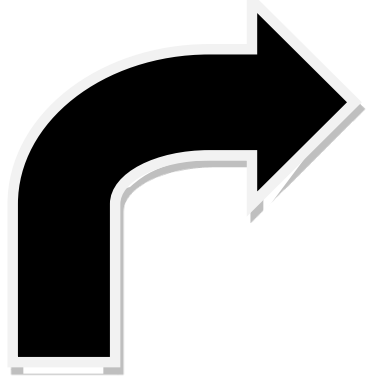

\begin{tabular}{|c|}
\hline Performance Phase \\
Self-Observation \\
Self-recording \\
Self-experimentation \\
Self-Control \\
Self-instruction \\
Imagery \\
Attention focusing \\
Task strategies \\
\hline
\end{tabular}

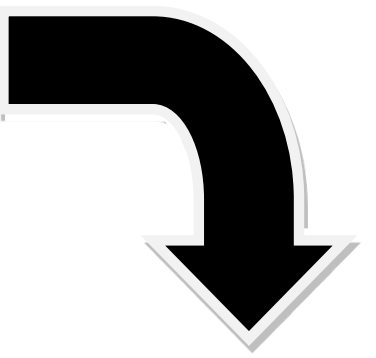

\section{Forethought Phase}

Task Analysis

Goal setting

Strategic planning

Self-Motivation Beliefs

Self-efficacy

Outcome expectations

Intrinsic interest/value

Goal orientation

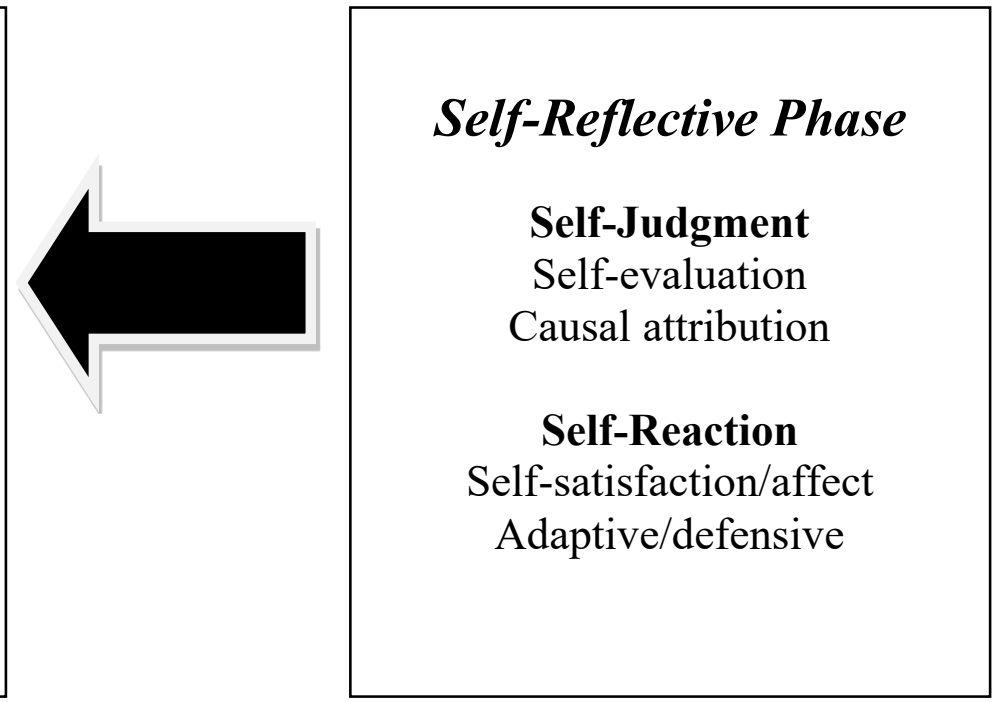


Self-Regulation and Mastery of Musical Skills 31

Figure 2
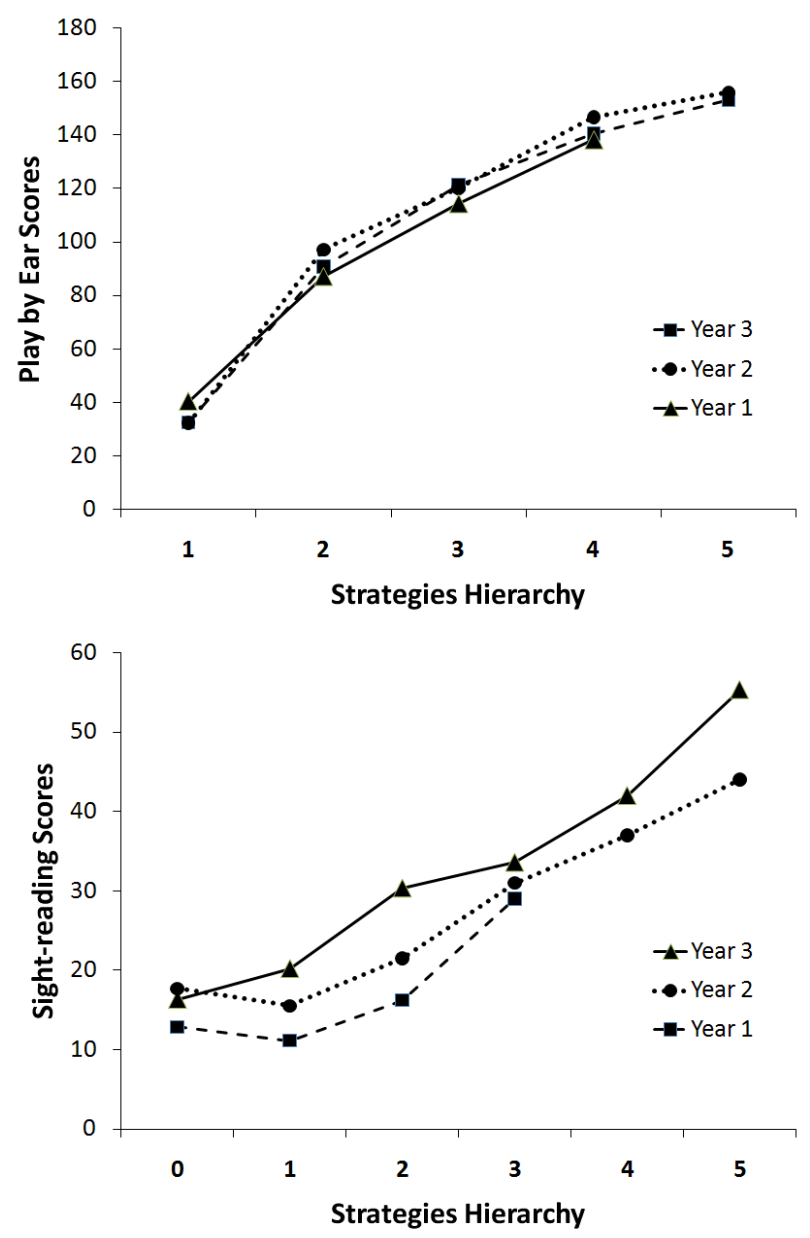
Figure 3

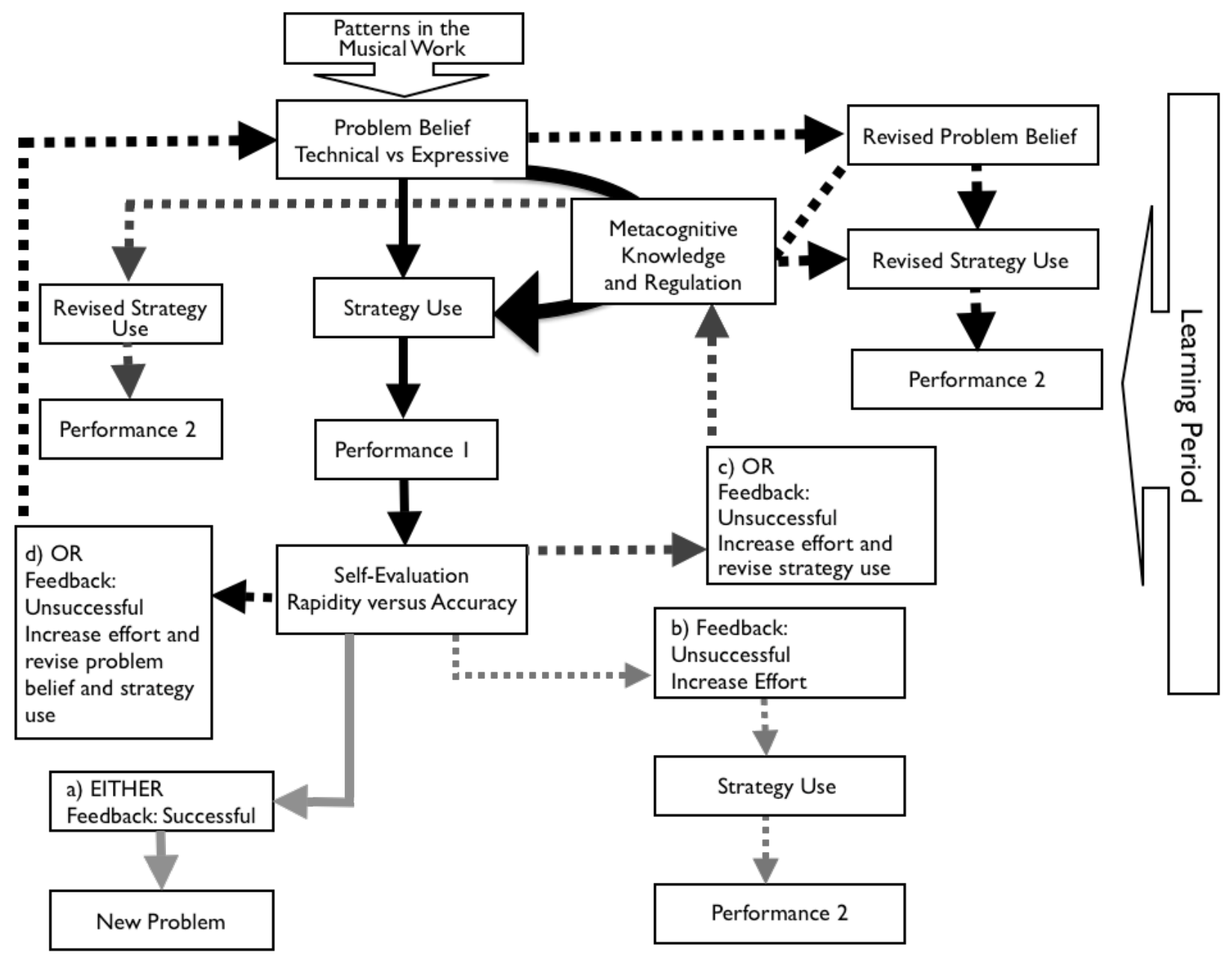


Figure captions:

Figure 1. Phases and subprocesses of self-regulation. From "Motivating Self-Regulated Problem Solvers" by B. J. Zimmerman and M. Campillo, 2003, in J. E. Davidson and R. J. Sternberg (Eds.), The Nature of Problem Solving, p. 239. New York: Cambridge University Press. Copyright 2003 by Cambridge University Press. Adapted with permission.

Figure 2. Connection between task-specific strategy use and results on two performance achievement measures during the first three years of learning an instrument (summary data from McPherson, 2005).

Figure 3. Cyclic self-regulation of learning strategies during practice, showing the basic first step and all four alternative problem-solving activities to follow it. From "Self-Regulating Learning Strategies in Instrumental Music Practice," by S. G. Nielsen, 2001, Music Education Research, 3, p.155. Copyright 2001 by Taylor \& Francis Ltd. Adapted with permission. 
Forethought, 5, 18, 20

Goal setting, 6

motivation, 2, 9, 11, 18, 21, 23, 24, 26, 27, 29

music

playing by ear, 7

practice, $3,6,9,10,11,12,13,16$

sight-reading, 7

performance phase, $5,10,13,16$

planning, 6,8

self-control, 14, 15

self-efficacy, 6, 9, 10, 18, 26, 27, 28, 30

self-observation, 14

self-reflection, 5,17

strategies, 4, 6, 7, 10, 11, 12, 13, 15, 16, 19, 20, 24, 28, 29, 35 


\section{University Library}

\section{- M M I N E R VA A gateway to Melbourne's research publications}

Minerva Access is the Institutional Repository of The University of Melbourne

Author/s:

Mcpherson, GEM;Renwick, J

Title:

Self-regulation and mastery of musical skills

Date:

2011

Citation:

Mcpherson, G. E. M. \& Renwick, J. (2011). Self-regulation and mastery of musical skills.

Zimmernan, BJ (Ed.). Schunk, DH (Ed.). Handbook of self-regulation of learning and performance, (1), pp.234-248. RoutledgeCurzon.

Persistent Link:

http://hdl.handle.net/11343/251870 